\title{
GAMBARAN PEMANFAATAN PELAYANAN KESEHATAN DI PUSKESMAS KELURAHAN PASIR KALIKI TAHUN 2017
}

\author{
Indra Karana Napitupulu ${ }^{1}$, Babygia Carolina ${ }^{2}$ \\ indrakelana2009@gmail.com
}

Program Studi Sarjana Keperawatan STIKes Dharma Husada Bandung

\begin{abstract}
ABSTRAK
Latar Belakang puskesmas merupakan pusat pembangunan masyarakat serta menyelenggarakan pelayanan masyarakat serta menyelenggarakan pelayanan masyarakat yang bermutu, merata, terjangkau dengan peran masyarakat secara aktif tuntutan masyaraka terhadap pemanfaatan Puskesmas semakin kompleks sebagai dampak positif kemajuan ilmu pengetahuan dan teknologi dari hasil pembangunan nasional bangsa Indonesia. Sebagai upaya untuk pelayanan kesehatan bagi masyarakat, maka setiap kecamatan di Indonesia telah memiliki lebih dari satu Puskesmas untuk seluruh Indonesia sebanyak 9754 unit, Puskesmas di Jawa Barat 1050 unit. Dengan demikian setiap 30 penduduk Indonesia rata - rata dilayani 1,15 dan 0,67 Puskesmas di Jawa Barat (Depkes RI, 2015). Di UPT Puskesmas Pasir Kaliki terdapat 6 kelurahan dengan jumlah penduduk yang dilayani 97494 orang dan jumlah KK 25467. Dan jumlah kunjungan ke UPT Puskesmas Pasir Kaliki sebanyak 44150. Dari jumlah tersebut dapat dilihat angka pemanfaatan sebesar 45,28\% ( Laporan UPT Puskesmas Paskal, 2015).

Tujuan penelitian adalah untuk mengetahui gambaran pemanfaatan pelayanan kesehatan di Puskesmas Kelurahan Pasir Kaliki Tahun 2017.

Metode penelitian adalah metode descriptive, dengan populasi adalah keluarga yang masuk di Kelurahan Pasir Kaliki Kota Bandung dengan kriteria jika dalam 1 Tahun terakhir ada anggota keluarga yang sakit dan pernah kepelayanan kesehatan. Metode pengambilan sampel yang digunakan adalah purposive. Jumlah sampel sebesar 95 orang. Analisis data yang digunakan dalam penelitian ini adalah analisis univariat, dan hanya disajikan distribusi frekuensi.

Hasil penelitian menunjukan bahwa responden yang memanfaatkan pelayanan kesehatan di UPT Puskesmas Pasir Kaliki Bandung sebanyak 80 orang (84.2\%) dan responden yang tidak memanfaatkan pelayanan kesehatan di UPT Puskesmas Pasir Kaliki Bandung sebanyak 15 orang $(15.8 \%)$.
\end{abstract}

Kata Kunci: Pemanfaatan Pelayanan Kesehatan.

\section{PENDAHULUAN}

Sistem Kesehatan Nasional (SKN) yaitu suatu tatanan yang menghimpun berbagai upaya bangsa indonesia untuk menjamin derajat kesehatan yang setinggitingginya. Pemerintah pusat dan pemerintah daerah perlu saling membantu dan melaksanakan pembangunan kesehatan secara terencana, terpadu dan berkesinambungan untuk mencapai derajat kesehatan yang tinggi (Depkes RI, 2008).

Derajat kesehatan dapat ditingkatkan dengan melaksanakan pelayanan kesehatan. Pelayanan kesehatan ini 
merupakan aspek yang penting untuk mewujudkan masyarakat yang mandiri untuk mencapai perilaku hidup yang sehat. Salah satu bentuk upaya penyelenggaraan upaya kesehatan dilaksanakan melalui pelayanan kesehatan Puskesmas.

Puskesmas merupakan pusat pembangunan masyarakat serta menyelenggarakan pelayanan masyarakat yang bermutu, merata, terjangkau dengan peran masyarakat secara aktif tuntutan masyarakat terhadap pemanfaatan Puskesmas semakin kompleks sebagai dampak positif kemajuan ilmu pengetahuan dan teknologi dari hasil pembangunan nasional bangsa Indonesia. Masyarakat semakin peka terhadap pemanfaatan Puskesmas yang bermutu sehingga tahu haknya tentang pemanfaatan Puskesmas yang seharusnya mereka terima. Meskipun sarana pelayanan kesehatan dasar telah terdapat di semua kecamatan dan di tunjang oleh tiga Puskesmas Pembantu namun upaya peningkatan belum dapat dijangkau oleh seluruh masyarakat, diperkirakan hanya sekitar $30 \%$ penduduk yang memanfaatkan pelayanan Puskesmas dan Puskesmas Pembantu (Depkes RI, 2008).

Dengan melihat kecilnya angka persentasi pemanfaatan pelayanan Puskesmas oleh masyarakat, khususnya keluarga yang merupakan bagian terkecil dari masyarakat, peneliti tertarik untuk melakukan kajian tentang “ Gambaran pemanfaatan pelayanan kesehatan di puskesmas kelurahan pasir kaliki tahun $2017 "$

\section{METODOLOGI PENELITIAN}

Data yang digunakan dalam penelitian ini adalah data primer. Populasi dalam penelitian ini adalah keluarga yang masuk di Kelurahan Pasir Kaliki Kota Bandung dengan kriteria jika dalam 1 tahun terakhir ada anggota keluarga yang sakit dan pernah kepelayanan kesehatan dan metode pengambilan sampel yang digunakan dalam penelitian ini adalah purposive (Sugiarto, 2001; Purwanto, 2003).

Pengumpulan data pada saat penelitian dilakukan dengan menyebarkan kuesioner kepada responden dan menjelaskan petunjuk pengisian kuesioner. Kemudian kuesioner yang telah diisi dikumpulkan dan dicek kelengkapannya oleh peneliti untuk diolah.

\section{HASIL DAN PEMBAHASAN}

\section{A. Hasil Penelitian}

Distribusi Responden Terhadap Variabel Dependen Di Wilayah Kerja UPT Puskesmas Pasir Kaliki Kota Bandung Tahun $2017 \quad(\mathrm{n}=95)$ diketahui bahwa sebagian besar 
responden memanfaatkan pelayanan kesehatan di UPT Puskesmas Pasir Kaliki Bandung, yaitu sebanyak 80 responden atau $84.2 \%$ sedangkan yang tidak memanfaatkan sebanyak 15 responden atau $15.8 \%$.

\section{B. Pembahasan}

Gambaran Pemanfaatan Pelayanan Kesehatan di Puskesmas.

Salah satu indikator untuk menilai bagaimana pemanfaatan Puskesmas sebagai Pusat pelayanan kesehatan oleh masyarakat adalah dari banyak atau tidaknya jumlah kunjungan ke Puskesmas tersebut. Rendahnya kunjungan masyarakat ke Pusat Pelayanan kesehatan menunjukkan bahwa masyarakat kurang memanfaatkan Pelayanan kesehatan Puskesmas.

Pemodelan pemanfaatan pelayanan kesehatan menurut Depkes RI (2010) memaparkan bahwa pemanfaatan fasilitas pelayanan kesehatan dipengaruhi oleh terbatasnya tenaga kesehatan milik pemerintah, keterjangkauan fasilitas pelayanan kesehatan oleh masyarakat dan persepsi masyarakat mengenai responsiveness pelayanan yang diberikan petugas kesehatan.
Banyaknya responden yang memanfaatkan pelayanan kesehatan pada penelitian ini dikarenakan pada saat melakukan penelitian dilaksanakan pada saat jam kerja.

Pemanfaatan Puskesmas Pasir Kaliki oleh masyarakat di tahun 2015 adalah 45,28\% dari jumlah penduduk kecamatan cicendo yang berjumlah 97494 jiwa dan lebih besar dari rata-rata nasional yang dikeluarkan oleh depkes RI tahun 2008 sebesar 30\%. Pemanfaatan Pelayanan Kesehatan di Puskesmas Pasir Kaliki dari hasil penelitian ini menunjukkan dalam 3 bulan terakhir sebagian besar masyarakat Kelurahan Pasir Kaliki memanfaatkan pelayanan kesehatan di Puskesmas dimana dari 95 responden menyatakan 80 responden $(84,21 \%)$ memanfaatkan pelayanan kesehatan di Puskesmas. Dan dari data yang terlihat responden yang memanfaatkan pelayanan kesehatan tersebut sebagian besar tidak bekerja dan merupakan ibu rumah tangga. Penelitian ini berbeda dengan penelitian Nuraini (2010) dimana hasil yang diperoleh adalah 
sebanyak $54 \quad(68,4 \%)$ responden tidak memanfaatkan pelayanan kesehatan sedangkan $25 \quad(31,6 \%)$ responden lainnya pernah melakukan utilisasi rawat jalan.

Dalam penelitian ini diperoleh hasil yang berbeda, hal ini disebabkan karena masyarakat makin memahami pentingnya pemeliharaan kesehatan sehingga mengunjungi Puskesmas tidak hanya untuk mencari pengobatan saja tetapi juga untuk memelihara kesehatannya agar terhindar dari penyakit (upaya preventif). Sebab lain adalah murahnya biaya berobat di UPT Puskesmas Pasir Kaliki dimana untuk setiap kali berobat, pasien hanya perlu mengeluarkan uang Rp.3000 bagi yang tidak memiliki asuransi dan tidak ada biaya untuk pasien yang memiliki asuransi. Hal ini membuat kenaikan jumlah pemanfaatan yang ada di UPT Pasir Kaliki. Sebagian masyarakat yang tidak memanfaatkan fasilitas kesehatan ini lebih memilih untuk pergi keklinik atau dokter umum yang berada didekat tempat tinggalnya. Selain itu lamanya antrian menyebabkan masyarakat terkadang enggan datang untuk berobat meskipun biaya di UPT Pasir Kaliki jauh lebih murah.

\section{SIMPULAN DAN SARAN}

\section{A. Simpulan}

1. Diketahui responden yang memanfaatkan pelayanan kesehatan di UPT Puskesmas Pasir Kaliki Bandung sebanyak 80 orang (84.2\%).

2. Diketahui responden yang tidak memanfaatkan pelayanan kesehatan di UPT Puskesmas Pasir Kaliki Bandung sebanyak 15 orang $(15.8 \%)$.

\section{B. SARAN}

1. Petugas Kesehatan

Diharapkan petugas kesehatan dapat lebih mempromosikan puskesmas sebagai pusat kesehatan masyarakat yang melayani promotif dan preventif bukan hanya sebagai pelayanan kuratif dan rehabilitatif. Meningkatkan mutu pelayanan kesehatan baik dengan meningkatkan kompetensi dan motivasi kerja serta meningkatkan pembinaan peran serta masyarakat melalui kelompokkelompok masyarakat yang terorganisir, misalnya: KPKIA (Kelompok Peminat Kesehatan Ibu 
dan Anak), UKK (Upaya Kesehatan Kerja) dan Kelompok Kesehatan remaja.

\section{Bagi Keluarga}

Diharapkan kepada keluarga terutama kepala keluarga agar dapat lebih mendukung lagi anggota keluarganya dalam memanfaatkan pelayanan kesehatan di Puskesmas, supaya kunjungan keluarga atau masyarakat dapat semakin meningkat.

\section{DAFTAR PUSTAKA}

Depkes RI. 2008. Laporan akuntabilitas kinerja kementrian kesehatan tahun 2008. Kementrian kesehatan. Jakarta.

Depkes RI. 2014. Undang-undang puskesmas. Pustaka Mahardika. Yogyakarta.

Depkes RI. 2015. Laporan akuntabilitas kinerja kementrian kesehatan tahun 2008. Kementrian kesehatan. Jakarta.

Purwanto, J. Editor: Sri Budianti. 2003. Dasar-dasar Metode Penarikan Sampel. Jakarta: STIS

Sugiarto, dkk. 2001.Teknik Sampling. Jakarta: PT Gramedia Pustaka Utama 